\section{Oil-spill danger to nesting birds}

Berkeley

A US oil cleanup crew last week reached the Antarctic Peninsula and stemmed the flow of diesel fuel from the wrecked Argentine supply ship Bahia Paraiso, which ran aground on 28 January near the US Palmer Base. The ship had already spilled two-thirds of its 250,000-gallon fuel supply. While the US team skimmed most of the recoverable fuel from the surrounding waters, an Argentine salvage crew prepared to remove the remaining 75,000 gallons of fuel remaining on the ship.

The biological consequences of the accident are now being evaluated. Unrecovered fuel has collected in shallow coves and inlets, where it has killed intertidal limpets, sponges and kelp, says Bernhard Lettau, National Science Foundation (NSF) programme manager for Polar Ocean Sciences, who recently arrived at the site. Lettau says the bottom-dwelling community may escape serious harm, as the water is relatively clear and free from particulate matter that could carry the fuel to the bottom.

But oil slicks less than $1 \mathrm{~mm}$ thick cannot be removed by skimming, so that a diesel sheen remains on much of the water in the area, according to Thomas Forhan, an NSF project manager at the site. He says that all traces of the volatile fuel should be gone within 10 days to a month, barring further leaks.

Forhan says that the ship, which is on its side in 40 feet of water, is unlikely to break up soon and that the Argentine salvage operation may take 3 to 4 weeks to recover the remaining fuel. He notes that the recovery entails the risk of further spills.

The effects of the spill on the area's krill population are unclear, according to Lettau. Deep-water animals have been less badly affected than shallow-water ones. But the spill has had a devastating impact on bird populations nesting near Palmer Base. Lettau says the breeding success of the South Polar skuas in the area "will be zero". Skuas lay two eggs in each nest, and usually only one chick survives to fledge.

But out of 53 nests inspected, only 6 had a living chick last week, and Lettau expects none of these to survive. He is unsure of the cause of death, but speculates that the chicks may be getting toxic doses of fuel in the food brought by their parents.

Lettau expects that the toll will be greatest among young birds, including penguin chicks, which fledge and take to the water in early February. Researchers at the base have begun banding chicks that have not yet left their rookeries, so as to trace their eventual fate. Marcia Barinaga

\title{
Japan grapples with definition of death by brain death
}

Tokyo

THE twenty-year controversy over the definition of brain death has entered a new phase. Last week, the Japanese Diet (parliament) was presented with new legislation that will eventually decide when the absence of electrical activity in the brain (brain death) can be considered to define the death of a person. At stake is whether surgeons may legally perform life-saving heart and liver transplant operations - both of which require the donation of living organs from brain-dead people.

The legislation, which seems certain to pass, would establish a special investigatory panel on brain death and organ transplants. The panel is modelled on the US Presidential Commission on Ethical Problems in Medicine and Biomedical and Behavioral Research which, in 1981 , accepted that brain death means death. But the new panel will take two to three years to reach its conclusions, which may be far too long for Japan's surgeons.

Already, a Niigata Prefecture hospital group has twice risked prosecution by performing a kidney transplant operation with an organ taken from a brain-dead patient. The first operation, last May, put the group in the odious position of having to face a legal suit for murder. Despite the risk of legal action, several other groups are eager to claim the prize of Japan's second heart transplant. The first, carried out in 1968, brought legal action and vilification for the surgeon concerned.

But now, after twenty years, a new force is propelling Japan towards acceptance of brain death. To Tokyo's embarrassment, Japanese are starting to travel abroad for transplant operations they cannot get at home. Last week, at almost the same time as the Ministry of Health and Welfare announced a new Tokyo research centre to help developing nations learn from Japan's 'advanced medical treatment' system, a fact-finding mission reported that eight Japanese patients were waiting in the Philippines for transplant operations. The mission, led by Representative Taro Nakayama (Liberal Democrat, Osaka), who has been active in promoting the new Diet legislation, also visited Australia, where it found that 22 Japanese had either received, or were waiting for, liver transplants.

With transplant organs in short supply everywhere in the world, Japanese patients in the hospitals of developing nations would seem especially incongruous. The Philippines is already considering legislative action to control visits by foreign patients.

Early last year, it seemed that Japan's brain-death problem was about to be resolved when the Japan Medical Association's Bioethics Council released a report urging that, subject to strict conditions, brain death should be accepted as a definition of death. Surgical groups at several hospitals immediately began to file applications with their own hospital ethical boards for permission to perform transplants.

But the momentum began to wane when the Japan Federation of Lawyers' Associations announced its opposition to the redefinition of death as brain death until a full social consensus had been reached. Subsequently, in May, the Japanese Society of Psychiatry and Neurology decided to come out against the redefinition.

At nearly the same time, a University of Tokyo patients' rights group instigated legal action for murder against those responsible for the Niigata Hospital kidney transplant. The group's view is that patients' rights are not adequately protected from surgeons wishing to carry out transplant operations. Although that view finds few supporters among physicians, public criticism inhibited further transplants from brain-dead patients in 1988 .

The Niigata group censured last year has already performed one kidney transplant from a brain-dead patient this year. According to relatives, the patient had expressed a wish to donate his organs in the event of his death.

Writers of Nihonjinron, a genre that explores supposedly unique characteristics of Japanese culture, have often asserted that the aversion to acceptance of brain death and transpiant operations is related to a Japanese view that body and soul are inseparable, or to confucian concepts that the body is a gift from one's parents that cannot be given away. But the Niigata man who left instructions for his organs to be donated is reported to have been much influenced by a television progamme on brain death.

The debate over definition of death has mostly subsided in the United States and Europe, with whole brain death being the commonly accepted criterion. Some have argued for extending the definition to include loss of higher brain function, but this has not gained acceptance. In most countries, solid organs may be retrieved from cadavers only with prior permission from the victim or the permission of relatives after death. But in France there is 'presumed consent', so that organs may be taken if needed over the objections of relatives unless the victim had previously made an express wish to the contrary.

Alun Anderson 